\title{
A study of head and eye movement in spasmus nutans
}

\author{
M. GRESTY AND J. LEECH \\ From the MRC Hearing and Balance Unit, Institute of Neurology, National Hospital for Nervous Diseases, \\ London
}

\author{
M. SANDERS AND H. EGGARS \\ From the Neuro-ophthalmology Department, National Hospital for Nervous Diseases, London
}

Spasmus nutans was first described by Raudnitz (1897) and although it is a rare clinical entity, it has been systematically documented by several authors (Cox, 1936; Norton and Cogan, 1954; Østerberg, 1937; Walsh, 1947; Wybar, 1971) all of whom have provided a characteristic clinical picture. All investigations of spasmus nutans have concluded that there is no relationship between the nystagmus and the head nodding because of the different frequencies involved. However, there are no reports in the literature of objective measurements of head and eye movements. Modern kinesiological recording methods are simple to perform and suitable for the recording of head movements. In addition recent studies of the normal patterns of head and eye co-ordination in man have helped in understanding the mechanisms involved (Mowrer, 1932; Hodgson and Lord, 1954; Crawford, 1960; Bartz, 1966; Fleming, Vossius, Bowman, and Johnson, 1969; Gresty, 1973, 1974).

The interrelationship of head and eye movements was recorded in a case of spasmus nutans using electro-oculographic techniques in conjunction with an optical method of recording head movements.

\section{Case history}

A 4-year-old-boy from Kuwait was referred for neuroophthalmological investigations.

At the age of $8 \frac{1}{2}$ months the parents had noticed rapid oscillatory eye movements. On beginning to walk they noted intermittent head nodding. This was marked initially but during the past year had improved. There was no history of neurological disorders and the family history was normal.

On examination there were intermittent episodes of horizontal and vertical oscillatory movements of small amplitude. They could be more marked in one eye or the other but seemed more marked in the abducting eye. On attempting convergence there was marked oscillation

Address for reprints: M. D. Sanders, FRCS, Neuro-ophthalmology Department, National Hospital for Nervous Diseases, Queen Square, London $\mathrm{WC}_{\mathrm{I}} \mathrm{N}_{3} \mathrm{BG}$ in the right eye. Ocular examination was otherwise normal with visual acuity of $6 / 5$ in each eye and normal fundus examination.

\section{EXPERIMENTAL METHOD}

The patient was seated in a chair in an upright position which did not obstruct freedom of head movements. He was fitted with a light, unobtrusive spectacle frame that carried sockets and leads for DC electro-oculographic (EOG) recording of the horizontal movements of the left and right eye. The ear pieces of the frame were linked around the back of the head with an elastic band, which supported a small ( $\mathrm{I}$ W) non-directional infrared emitter on the occipit.

A Schottky barrier (United Detector Technology $\mathrm{SC} / 25$ ) linear motion photo detector was mounted with its sensitive surface in the focal plane of a $35 \mathrm{~mm}$ camera. The axes of the detector were orientated horizontally and vertically. The camera was placed to view the back of the patient's head. As the patient moved his head the detector gave $x, y$ co-ordinate readouts of the linear motion of the infrared source which were sinusoidally related to the head rotation. Since the headnodding consisted of small amplitude oscillatory rotations in the horizontal plane the $x$ axis of the detector provided a signal which was approximately a linear function of head displacement. The patient was examined experimentally for two I $\frac{1}{2}$-hour periods while continuous recordings were taken. Emphasis was laid on determining the specific stimuli which evoked the nystagmus and head movement and their interrelationships.

\section{Results and discussion}

Detailed characteristics of the head nodding and ocular movements which could not be determined by inspection were clarified by the recordings. The nystagmus consisted of a high-frequency (i I Hz) sinusoidal, convergence movement of both eyes (Fig. 2, upper traces). The peak to peak amplitude of oscillation was about $2^{\circ}$. During these oscillations some jerk-type nystagmus to the left occasionally occurred (Fig. I, eye movements with stationary head). The head nodding consisted of a $3-\mathrm{Hz}$ sinusoidal horizontal oscillation of the head with a peak to peak amplitude of about $3^{\circ}$ (Fig. 2, lower traces). During the head nodding, perfectly 

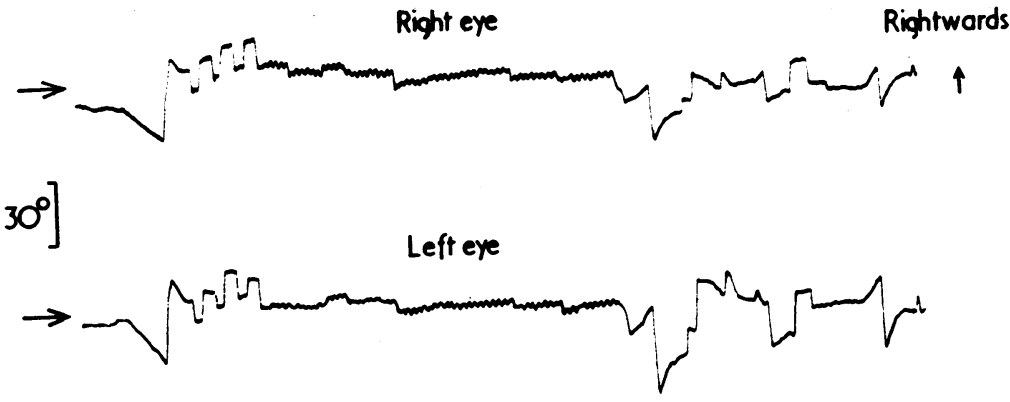

FIG. I Displacements in horizontal plane of head and eyes recorded in a case of spasmus nutans. Horizontal arrows indicate primary gaze and primary head position. High frequency eye movements present during periods of quiescent head movement represent nystagmus of spasmus nutans

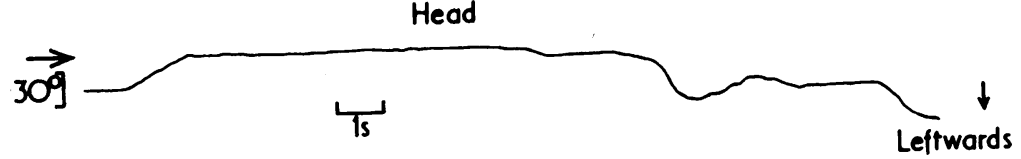

normal compensatory eye movements were present (Fig. 2, lower traces).

Further examination of the head and eye movement recordings revealed consistently reproducible features which, to our knowledge, have not hitherto been reported and would appear to have important implications for understanding the nature of the disorder.

Of utmost importance is the consistent finding that the head nodding (Fig. 2, lower traces) always abolished the eye movements (Fig. 2, upper traces). The nodding was specifically elicited by novel

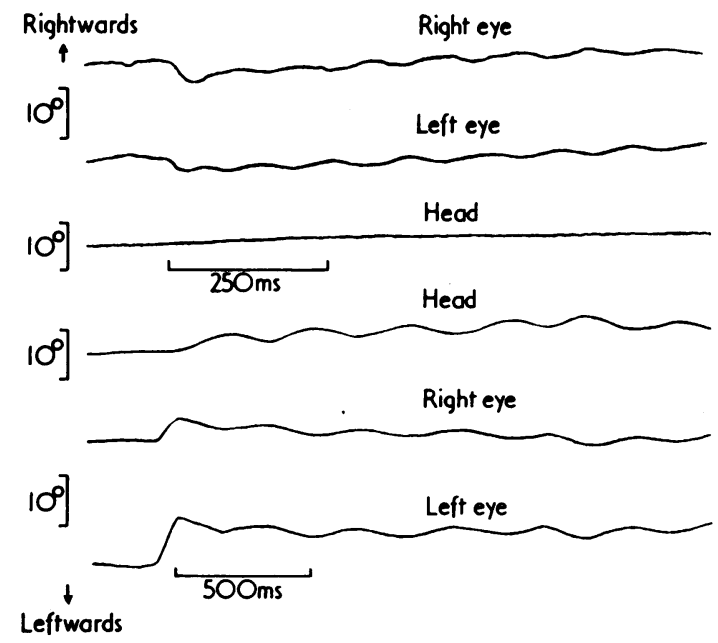

FIG. 2 Displacement in the horizontal plane of the head and eyes in a case of spasmus nutans. Upper traces; head stationary, eyes executing pathological convergence oscillation. Lower traces; head nodding, eyes executing normal compensatory movements of vestibular origin stimuli (the most powerful being an unknown face) to which intense attention was paid. Hence it would appear that the head nodding is a mechanism which permits the discrimination of the finer features of a visual stimulus. In place of the abolished pathological nystagmus the eyes perform purely compensatory movements which aid vision during head displacements (Benson and Guedry, 1971). The frequency of the head nodding is well within the range of principal natural frequency components of voluntary head movements in humans ( $I$ to ${ }_{4} \mathrm{~Hz}$ ). The tentative hypothesis may be made that the head nodding is not pathological in origin but may be considered to be an operant-conditioned response which, because of its powerful ability to supress the pathological nystagmus, is an adaptive behavioural pattern.

There is some evidence against the hypothesis. Case histories are divided between those in which the parents report that head nodding had an earlier onset than eye nystagmus and those reporting the inverse sequence.

The nystagmus is abolished not only by head nodding but also by any head movements of significant amplitude (Fig. I, later portions of the head movement trace). Isolated head movements of small amplitude $\left(2^{\circ}\right.$ to $\left.3^{\circ}\right)$ did not necessarily abolish the nystagmus. It may be the case that in small children there is no requirement for prolonged periods of visual fixation so that any amplitude and frequency of head movement can be employed to abolish the nystagmus. In older children, such as the patient described here, prolonged fixation is required and as a consequence the suppressive head nodding becomes more refined. This consideration may explain the variety of movements reported in spasmus nutans. The small amplitude and high frequency of the refined head nodding produces, as 
in normal subjects, a purely compensatory eye movement (Benson, 1969).

The origin of the nystagmus is more in doubt than that of nodding. The nystagmus has a basic high-frequency component similar to the principal frequency components of saccadic eye movements (Barnes, 1973); therefore it is possible that the origin lies entirely in an imbalance of the saccadic pulse generating mechanism. It is envisaged that each eye is supplied with a high frequency train of saccadic pulses, alternately adducting and abducting the globe and producing an overall plant response in the form of sinusoidal oscillation.

\section{Conclusions}

The tentative hypothesis is made that head nodding in spasmus nutans is an operant-conditioned phenomenon which, by suppressing the pathological, high-frequency nystagmus aids visual acuity. It is not pathological per se but epiphenomenal. The eye nystagmus appears to be a disorder of the saccadic pulse generating mechanism(s). These conclusions were drawn from intensive observation of a single case of spasmus nutans. More information about the developmental history and patterns of motor co-ordination is needed before valid generalizations may be made but the low incidence of spasmus nutans impedes the satisfaction of this requirement.

\section{Summary}

A case of spasmus nutans was studied using objective recordings of head and eye displacement in order to generate a precise description of the ocular oscillations and head nodding and to investigate their interrelationships. The ocularoscillations consisted of $1 \mathrm{I}-\mathrm{Hz}$ sinusoidal convergence movements. The head nodding consisted of a $3-\mathrm{Hz}, 3^{\circ}$ peak to peak, sinusoidal oscillation in the horizontal plane. The occurrence of the nodding always abolished the ocular oscillation which was replaced by normal compensatory eye movements which assisted visual acuity. The hypothesis is made that the head nodding is not pathological; it is a learned behavioural pattern which permits the patient to nullify the pathological eye movements. In order to test this hypothesis further, objective evidence is required to determine the precise order of appearance of the abnormal head and eye movements in spasmus nutans.

We wish to thank Dr K. J. Zilkha for allowing us to study and publish his case.

\section{References}

BARNes, G. R. (1973) Royal Air Force Institute of Aviation Medicine Report No. 529, I

BARTZ, A. E. (1966) Science, 152, 1644

BENSON, A. J. (1969) Interactions between semicircular canals and gravireceptors, in : 'Recent Advances in Aerospace

Medicine. Proc. XVIII Intl. Congress of Aviation and Space Medicine', ed. Douglas E. Busby. Reidel, Holland - and GUEDRY, F. E. (1971) Aerospace Med., 42, 593

cox, R. (1936) Arch. Ophthal. (Chic.), 15, 1032

CRAWFORD, w. A. (1960) Visual Acuity and Moving Objects III. The Co-ordination of Eye and Head Movements.

Gt. Brit. Fly Personnel C: 1-9 Res. Comm. 130

fleming, D. G., vossius, w., bowman, F., and johnson, E. L. (1969) Ann. N.Y. Acad. Sci., 156, 825

GRESTY, M. A. (1973) Agressologie, 14, A 7

(1974) Vision Res., 14, 395

HODGSON, F., and LORD, MARY P. (1954) Nature (Lond.), 174, 75

MOWRER, O. H. (1932) Ann. Otol. (St Louis), 4I, 412

NORTON, E. W. D., and COGAN, D. G. (1954) Arch. Ophthal., 52, 442

ØSTERBERG, G. (1937) Acta ophthal (Kbh.), 15, 457

RAUDNITZ, R. W. (1897) $\boldsymbol{y b}$. Kinderheilk., 45, 145

WALSH, F. B. (1947) 'Clinical Neuro-ophthalmology', pp. 316-318. Williams \& Wilkins, Baltimore

WYBAR, K. (197I) Ann. Ophthal., 3, 645 